48

\title{
EXPOSURE TO CARBON BLACK AND LUNG CANCER \\ RISK IN A MULTICENTRE CASE-CONTROL STUDY IN CENTRAL AND EASTERN EUROPE AND THE UNITED KINGDOM
}

Nualnong Wongtongkam, ${ }^{1}$ Ann Olsson, ${ }^{2}$ Maria Leon Roux, ${ }^{2}$ Anush Mukeriya, ${ }^{3}$ Neonila Szeszenia-Dabrowska, ${ }^{4}$ Peter Rudnai, ${ }^{5}$ Jolanta Lissowska, ${ }^{6}$ Eleonora Fabianova, ${ }^{7}$ Adrian Cassidy, ${ }^{8}$ Dana Mates, ${ }^{9}$ Vladimir Bencko, ${ }^{10}$ Lenka Foretova, ${ }^{11}$ Vladimir Janout, ${ }^{12}$ Joelle Fevotte, ${ }^{13}$ Tony Fletcher, ${ }^{14}$ Andrea 't Mannetje, ${ }^{15}$ Paul Brennan, ${ }^{2}$ Paolo Boffetta, ${ }^{16}$ Kurt Straif ${ }^{2}$ Flinders University, Adelaide, Australia: ${ }^{2}$ IARC, Lyon, France; ${ }^{3}$ Cancer Research Center, Moscow, Russia; ${ }^{4}$ Nofer Institute of Occupational Medicine, Lodz, Poland; ${ }^{5}$ National Institute of Environmental Health, Budapest, Hungary; ${ }^{6}$ Institute of Oncology, Warsaw, Poland; ${ }^{7}$ Specialized State Health Institute, Banska Bystrica, Slovakia; ${ }^{8}$ University of Liverpool, Liverpool, UK; ${ }^{9}$ Instituteof Hygiene, Bucharest, Romania; ${ }^{10}$ Charles University, Prague, Czech Republic; ${ }^{11}$ Masaryk Institute, Brno, Czech Republic; ${ }^{12}$ Palacky University, Olomouc, Czech Republic; ${ }^{13}$ InVS/DST, Saint Maurice, France; ${ }^{14}$ LSHTM, London, UK; ${ }^{15}$ Massey University, Wellington, New Zealand; ${ }^{16}$ Mount Sinai School of Medicine, New York, USA

\subsection{6/oemed-2011-100382.48}

Objectives We estimated the lung cancer risk following occupational exposure to carbon black while adjusting for smoking, and explored the effect of time-windows of carbon black exposure since recent studies have hypothesised that recent exposure is the most important time-window for carbon black exposure.

Methods The multicenter case-control study on lung cancer was conducted from 1998 to 2002 in seven European countries; 2861 cases and 2936 controls were recruited. Occupational and socio-demographic information was collected through interviews. Industrial hygiene experts in each country evaluated exposure to 70 occupational agents, including carbon black. Unconditional logistic regression models were applied to calculate ORs and $95 \%$ CIs adjusting for centre, sex, other occupational exposures and tobacco smoking.

Results The OR for ever exposure to carbon black was 1.64 (95\% CI 1.09 to 2.46). We observed a significant dose-response trend for maximum intensity ( $\mathrm{p}$-value, 0.02 ) and average intensity ( $p$-value, 0.03 ). The OR for the highest exposure category of cumulative exposure in the last 15-years was OR 3.32 (95\% CI 1.22 to 9.03 ).

Conclusions The results show an association between occupational exposure to carbon black and lung cancer risk, and a significant dose-response relationship with increasing intensity. The most recent 15 years appear to be the most relevant time of exposure. 